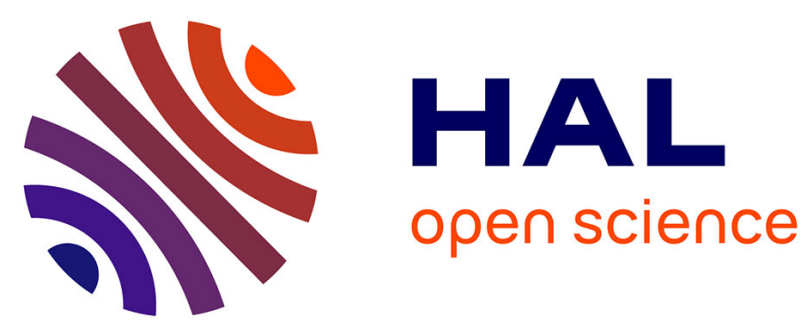

\title{
Differential impairments in irony comprehension in brain-damaged individuals: Insight from contextual processing, theory of mind, and executive functions.
} Natacha Cordonier, Marion Fossard, Maud Champagne-Lavau

\section{> To cite this version:}

Natacha Cordonier, Marion Fossard, Maud Champagne-Lavau. Differential impairments in irony comprehension in brain-damaged individuals: Insight from contextual processing, theory of mind, and executive functions.. Neuropsychology, 2020, 34 (7), pp.750-763. 10.1037/neu0000682 . hal02996068

\section{HAL Id: hal-02996068 \\ https://hal.science/hal-02996068}

Submitted on 9 Nov 2020

HAL is a multi-disciplinary open access archive for the deposit and dissemination of scientific research documents, whether they are published or not. The documents may come from teaching and research institutions in France or abroad, or from public or private research centers.
L'archive ouverte pluridisciplinaire HAL, est destinée au dépôt et à la diffusion de documents scientifiques de niveau recherche, publiés ou non, émanant des établissements d'enseignement et de recherche français ou étrangers, des laboratoires publics ou privés. 
Running head: Heterogeneity of neuropsychological and pragmatics profiles

Published in Neuropsychology, 1-51, 2020, which should be used for any reference to this work. (c) 2020, American Psychological Association. This paper is not the copy of record and may not exactly replicate the final, authoritative version of the article. Please do not copy or cite without authors' permission. The final article will be available, upon publication, via its DOI: 10.1037/neu0000682

Differential impairments in irony comprehension in brain-damaged individuals: Insight from contextual processing, theory of mind and executive functions

Natacha Cordonier ${ }^{1,2}$, Marion Fossard ${ }^{1}$, Maud Champagne-Lavau ${ }^{2}$

1. Faculté des lettres et sciences humaines, Institut des sciences logopédiques, Université de Neuchâtel, Neuchâtel, Suisse

2. Aix-Marseille Univ, CNRS, LPL, Aix-en-Provence, France

\section{Author Note}

Corresponding author: Natacha Cordonier, Université de Neuchâtel, Rue Pierre-à-Mazel 7 2000 Neuchâtel, Suisse, Phone: (+41) 3271817 34, email: natacha.cordonier@unine.ch Acknowledgment: We express our sincere gratitude to all the participants of the study and to the neuropsychologists who helped recruit patients in the institutions, in particular: Virginie Descloux, Aline von Siebenthal and Camille Herrmann (Hôpital Fribourgeois), Victorine Zermatten (Valais de Coeur), Anne Bellman, Christelle Aubert and Emilie Byland (Clinique Romande de réadaptation) and Delphine Frochaux (Hôpital Neuchâtelois).

Conflict of interest: The authors declare they have no conflict of interest

Fundings: This work was supported by Swissuniversities under Grant number FR17/19 to Natacha Cordonier 
Running head: Heterogeneity of neuropsychological and pragmatics profiles

\begin{abstract}
Objective: The comprehension of irony can be affected after brain injuries. The cognitive mechanisms accounting for such disorders remain yet unclear. The heterogeneity of cognitive profiles of brain-damaged individuals and the use of independent tests to measure the links between these mechanisms and the comprehension of irony might contribute to this lack of clarity. The present study aimed to further explore the underlying mechanisms of irony understanding disorders (i.e., context processing, executive functions (EF), and theory of mind (ToM)) in patients with brain lesions. Method: We used a paradigm manipulating these mechanisms within an irony task to identify different patterns of pragmatic performance associated with cognitive profiles. We administered this task and standard neuropsychological tests assessing EF, and ToM to thirty acquired brain injured (ABI) and thirty healthy control (HC) participants. Results: A cluster analysis revealed that two-thirds of the ABI participants (3 sub-groups out of 4) presented atypical pragmatic and neuropsychological patterns. The most severe disturbances in understanding irony, characterized by insensitivity to the context, were associated with a joint impairment on ToM and EF in one subgroup. In the two other context-sensitive subgroups, an isolated deficit in EF co-occurred with difficulties dealing with literal or ironic statements when the EF demand of the irony task was increased. However, the effect of this EF demand could be negated by the presence of markers helping the comprehension of irony. Conclusions: These results have important clinical implications for the evaluation and therapy of pragmatic disorders in ABI individuals.
\end{abstract}

Keywords: irony; context processing; theory of mind; executive functions; right brain injury 
Running head: Heterogeneity of neuropsychological and pragmatics profiles

\section{Key Points}

Question: Explore the role of three cognitive mechanisms - context processing, executive functions and theory of the mind - in the comprehension of irony in patients with ABI

Findings: There are distinct ABI subgroups, defined by different associations between these mechanisms and the understanding of irony.

Importance: These cognitive mechanisms and the pathological profiles related to them should be considered in the development of assessment tools and therapies.

Next steps: The effectiveness of treatments targeting these cognitive mechanisms on the comprehension of irony should be further explored. 
Running head: Heterogeneity of neuropsychological and pragmatics profiles

Differential impairments in irony comprehension in brain-damaged individuals: Insight from contextual processing, theory of mind and executive functions

Irony is a form of non-literal language, where the speaker says something but means something else, most commonly the opposite of what has been said (Gibbs, 1986). Let's imagine that Suzanne and Alexander plan to picnic in the mountains, but the weather is just horrible: It's raining cats and dogs, and it's windy. Before they leave, Suzanne tells Alexander: "We are lucky with the weather." With the help of context, it's easy for Alexander to understand that the statement is ironic, and that what Suzanne really means is that they are unlucky with the weather. Ironic utterances are relatively common in everyday life. They appear in $8 \%$ of conversational tours with friends (Gibbs, 2000) and approximatively five times per episode of American comedies (Dews and Winner, 1997). Poor comprehension of irony, as it creates communication disorders, can thus impact social and professional integration (Dahlberg et al., 2006; Hofgren, Esbjörnsson \& Sunnerhagen, 2010; Meulenbroeck \& Turkstra, 2016).

Many patients with acquired brain injuries (ABI), following traumatic brain injury (TBI) or stroke in the right hemisphere (RHD), may experiment difficulties understanding irony (see Lundgren \& Brownell, 2016 and Rowley, Rogish, Alexander \& Riggs, 2017 for reviews). Not all ABI individuals, however, have such pragmatic deficits and several studies have shown a significant heterogeneity of pragmatic disorders in TBI or RHD populations (Blake, Duffy, Myers \& Tompkins, 2002; Champagne-Lavau, Cordonier, Bellmann \& Fossard, 2018; Champagne-Lavau \& Joanette, 2009; Côté, Payer, Giroux \& Joanette, 2007; Dardier et al., 2011; McDonald \& Pearce, 1996). Given the prevalence and the heterogeneity of the disorders of non-literal language comprehension, one of the current challenges is to better 
Running head: Heterogeneity of neuropsychological and pragmatics profiles

understand the cognitive processes underlying these difficulties and to propose personalized and targeted therapies accordingly. The main goal of the present study was thus to investigate underlying mechanisms likely to account for difficulties in irony understanding in the ABI population. To take the heterogeneity into account, a cluster analysis was used in the present study enabling us to identify different pragmatic profiles based on the performances of ABI individuals in an irony task. Three mechanisms reported in the literature were considered in this study and are described below: contextual processing, executive functions (EF) and theory of mind (ToM) (see Martin \& McDonald, 2003 for a review).

Understanding irony requires the integration of different types of contextual information. The perception of an incongruity between the context and the target statement is known to be an essential condition for understanding irony (Ivanko \& Pexman, 2003; Kreuz \& Glucksberg, 1989; Rivière, Klein \& Champagne-Lavau, 2018). Other markers, although not necessary, may also help (Attardo, 2000). This is the case of the characteristics of the speakers, such as their professional occupation and the stereotypes attached to them: An ironic statement is judged more likely if produced by a comedian than by a priest (Pexman \& Olineck, 20002). The presence of lexical markers, such as hyperbolic terms, within the utterance, also facilitate the understanding of irony (e.g., we are extremely lucky with this amazing weather!) (Kreuz \& Roberts, 1995).

Several researchers have suggested that some ABI patients may have difficulty detecting or using relevant contextual information to understand irony (Blake, 2010). Champagne-Lavau et al. (2018) demonstrated that a subgroup of RHD patients showed a lack of sensitivity to contextual incongruity in the interpretation of ironic utterances. In the same way, Kaplan, Brownell, Jacobs \& Gardner (1990) highlighted that RHD participants used only information about the actor's performance - not information about the relationship between characters - to 
Running head: Heterogeneity of neuropsychological and pragmatics profiles

judge whether the statement was ironic or truthful, as opposed to healthy subjects. However, some studies tend to show that ABI patients can make inferences when the context is sufficiently strong - strong contextual bias inducing the inference (Blake, 2009) or the presence of several contextual cues (McDonald \& Flanagan, 2004). To our knowledge, no irony task has so far manipulated the strength of the context in terms of the absence or presence of markers inducing the comprehension of irony, such as speaker occupation stereotypes and lexical markers in ABI patients. The present study will seek to overcome this lack.

A second cognitive process, theory of mind (ToM), is critical to understanding irony. This ability to attribute mental states to others (Premack \& Woodruff, 1978) allows us to bridge the gap between the literal meaning of a sentence and the intended meaning. It is thanks to inferences on the intention of the speaker that an interlocutor can perceive irony (Grice, 1957).

The links between ToM and comprehension of irony have been extensively highlighted through clinical and neuroimaging studies. Indeed, it is well established that deficits in ToM may result from a brain injury (for reviews, see Martin-Rodriguez \& León-Carrión, 2010, McDonald, 2013 and Weed, 2008). These deficits of theory of the mind, and particularly second-order ToM, co-occurred with difficulties in understanding irony in many ABI patients (Channon, Pellijeff \& Rule, 2005; McDonald \& Flanagan, 2004; Shamay-Tsoory, Tomer \& Aharon-Peretz, 2005; Winner, Brownell, Happé, Blum \& Pincus, 1998; for a review see Rowley et al.,2017). Moreover, several studies using neuroimaging methods have shown the activation of a neural ToM network - left and right temporal-parietal junction, medial prefrontal cortex, and precuneus - when performing a task of irony understanding (Eviatar \& Just, 2006; Shibata, Toyomura, Itoh \& Abe, 2010; Spotorno, Koun, Prado, Van Der Henst \& 
Running head: Heterogeneity of neuropsychological and pragmatics profiles

Noveck, 2012; Uchiyama et al., 2006; Wakusawa et al., 2007). Only one study (Martin \& McDonald, 2005) found no association between measures of ToM and the comprehension of irony in patients with TBI. These authors suggested a role of general inferential reasoning rather than theory of mind to account for irony comprehension.

Finally, deficits in executive functions (EF) could also, at least in part, account for difficulties in understanding irony. The term EF refers to a set of cognitive control processes (e.g., inhibition, flexibility, working memory) which enable us to adapt our behavior in various goal-oriented situations (Miyake et al., 2000). EF would thus be strongly solicited in irony, insofar as the intentional meaning changes according to the context. Intact EF enable us to alternate rapidly between literal and non-literal meanings and to inhibit salient but irrelevant literal meaning in a given context.

It is widely accepted that EF are mediated by networks, involving in particular, the frontal lobes (Bettcher et al., 2016), and that they are frequently impaired after a brain injury (Channon \& Watts, 2003; Honan, McDonald, Gowland, Fisher \& Randall, 2015; Zinn, Bosworth, Hoenig \& Swartzwelder, 2007; see McDonald, Flashman \& Saykin, 2002 for a review). The relationship between EF and the comprehension of non-literal language is however, more controversial. When EF are considered on the whole, hierarchical regression analysis suggests that working memory, cognitive flexibility, and planning, contribute to the comprehension of irony (Bosco, Gabbatore, Angeleri, Zettin \& Parola, 2018; Bosco, Parola, Sacco, Zettin \& Angeleri, 2017). In a recent meta-analysis, Rowley and colleagues (2017) also demonstrated that the correlation between pragmatic understanding and $\mathrm{EF}$, was from moderate to strong. On the other hand, the different EF, considered individually, do not seem to correlate to the understanding of irony in the same way. Indeed, flexibility skills are generally not related to measures of comprehension of non-literal language (McDonald, 2000; 
Running head: Heterogeneity of neuropsychological and pragmatics profiles

Champagne, Desautels \& Joanette 2004; Martin et McDonald, 2005; McDonald et al. 2006; McDonald, Fisher, Flanagan \& Honan, 2017; Shamay-Tsoory et al., 2005), although an association between flexibility measures (TMT, Reitan \& Wolfson, 1993 and WCST, Heaton, 1981) and non-literal comprehension has been found in two studies (McDonald et al., 2006; Zimmermann, Gindri, Oliveira \& Fonseca 2011). Similarly, the links between working memory and the comprehension of non-literal language are more contrasted, some studies have found links (Channon \& Crawford, 2010; McDonald et al., 2006, 2017; Zimmermann et al., 2011) and others have not (Channon et Watts, 2003; Martin et McDonald., 2005). On the contrary, the role of inhibition in pragmatic understanding seems more obvious, as all studies we know of, have demonstrated a positive association between these two capacities (Champagne et al., 2004; Champagne-Lavau \& Joanette, 2009; Channon \& Crawford, 2010; Channon \& Watts, 2003; McDonald et al., 2014). To explain the lack of consensus between EF and non-literal language comprehension, many studies have put forward the hypothesis of a joint involvement of the ToM and EF in the understanding of non-literal language (Bosco et al., 2017; Byom \& Turkstra, 2017; Champagne-Lavau \& Joanette, 2009; Honan et al., 2015; McDonald et al., 2014). In addition, several studies (Byom \& Turkstra, 2017; Honan et al., 2015; McDonald et al., 2014) have suggested that discourse and ToM disorders may be related to the cognitive demand of the task: Increasing demand in EF would reduce the ability of brain-injured patients to infer the mental states of others, such as ironic intent.

To summarize, many studies have focused on the relationship between ToM, EF, and irony comprehension. However, the tasks used, vary significantly from one study to another, and the relationships are usually measured by independent measures (McDonald et al., 2014). Byom and Turkstra (2017) suggested that «a stronger method for examining the relationships between cognitive processes and social communication is to manipulate the theory of mind 
Running head: Heterogeneity of neuropsychological and pragmatics profiles

and executive function demands of the communication task itself » (p.3). Nowadays, few authors have attempted to manipulate the cognitive processes involved in the comprehension of non-literal language directly within the tasks created (Honan et al., 2015). Otherwise, the characteristic heterogeneity of brain-injured populations has rarely been considered in the analyses (Blake, 2017)

Therefore, the present study aimed to further explore the underlying mechanisms of irony understanding disorders - context processing, ToM, and EF - in ABI patients. To this end, we designed a written irony task, which directly manipulated, within the task, (1) the context (presence or absence of contextual markers inducing irony) and (2) the EF demand (low or high). The presence of ironic and literal conditions allowed us to evaluate ToM through a question about the intention of the speaker ("What does X mean?") which was asked at the end of each story. Standard ToM and EF tests were also administered. It was hypothesized that $\mathrm{ABI}$ participants would be more sensitive to the presence of multiple markers of irony in the context and EF demand than the healthy subjects. In line with the current literature, we also aimed to determine whether or not $\mathrm{ABI}$ participants exhibited different pragmatic profiles associated with different neuropsychological performances. It was hypothesized that:

1) Deficits in ToM will manifest in difficulties to understand irony in all conditions, regardless of the presence of markers of irony or EF demand. This lack of sensitivity to the context will manifest itself primarily by errors of literal interpretations in ironic conditions. 2) $\mathrm{EF}$ - especially inhibition - deficits will increase errors in the interpretation of literal and ironic statements in conditions with high EF demand. We expect erroneous literal and non-literal interpretations related to uninhibited irrelevant information.

3) Concomitant deficits in ToM and EF will result in difficulties in all ironic conditions. These difficulties could be exacerbated in ironic conditions with high EF demand. 
Running head: Heterogeneity of neuropsychological and pragmatics profiles

4) The absence of markers of irony in the stories will exacerbate the difficulties described in hypothesis 2) and 3). The condition with high EF demand and without markers of irony will be the ones in which participants with EF deficits will fail more frequently.

5) ABI participants will vary in the extent to which they manifest these difficulties.

\section{Methods}

\section{Participants}

Thirty participants (18 males, 12 females) with chronic acquired brain injury (ABI) were recruited from the outpatient records of a number of hospitals and clinical centers in the French part of Switzerland (Hôpital Fribourgeois (HFR), Hôpital Neuchâtelois (HNE), Clinique romande de réadaptation and Foyer Valais de Coeur). All participants met the following inclusion criteria: they were between 18 and 65 years old and native French speakers; they received the medical diagnosis of stroke in the right hemisphere or moderateto-severe TBI (Glasgow Coma Scale score of 13 or below or post-traumatic amnesia (PTA) of at least 24 hours (Maas et al., 2008; Teasdale \& Jennett, 1974)); they were at least six months post-brain injury. Exclusion criteria included previous psychiatric or alcoholic history, reading difficulties or aphasia according to neuropsychological reports and scores on DTLA (Détection des Troubles du Langage chez l'Adulte et la personne âgée; Macoir et al., 2017) or a reading subtest of MT-86 test (Nespoulous et al., 1992). Thirteen of the sample had sustained a stroke in the right hemisphere and seventeen had a history of a moderate to severe traumatic brain injury (nine in road traffic accidents and eight in falls). Mean time since injury for all participants was 44.3 months $(\mathrm{SD} \pm 43.67)$, while duration of PTA, taken from neuropsychological reports for 11 of the 17 participants with TBI, was 35.7 days (SD \pm 
Running head: Heterogeneity of neuropsychological and pragmatics profiles

44.51). Further clinical details, including clinical, radiological MRI or CT reports, are available in Table 1.

Thirty healthy participants (HC; 12 males, 18 females) with similar demographic characteristics and no previous neurological history were also recruited in the local community. Exclusion criteria included psychiatric or alcoholic history, reading disabilities, and a score below 26 on the Montreal Cognitive Assessment (MoCA; Nasreddine et al., 2005), a screening tool for neurocognitive impairment. They were matched with the ABI participants for age (ABI mean: 51.07, SD: 10.74, HC mean: 51.2, SD: 10.59; $t(58)=0.48, p$ $>.05$ ) and level of education (ABI mean: 12.83, SD: 2.42, HC mean: 12.83, SD: $2.57 ; t(58)=$ $0.01, p>.05)$

The study was approved by the local ethics committee (Commission cantonale d'éthique de la recherche sur l'être humain - CER-VD) and all participants had given their written informed consent before inclusion in the study.

\section{INSERT TABLE 1}

\section{Materials and procedure}

All participants were tested individually in a quiet room, for between 1 and 4 sessions depending on their level of fatigability. They were assessed with regard to their executive functions capabilities, theory of mind abilities and irony understanding. The order of administration of the tests was counterbalanced between the participants. 
Running head: Heterogeneity of neuropsychological and pragmatics profiles

Standard instruments. Executive functions. Standardized neuropsychological tests were used to evaluate executive functions in all participants. Inhibition was assessed with the French version of the Hayling test (Rouleau, 1998), where participants had to complete sentences with the expected word (automatic condition) or an unexpected word (inhibition condition). Two scores (automatic and inhibition scores), based on response accuracy and response latencies in each condition, were calculated according to Burgess and Shallice (1997). The verbal fluency (letters D (DTLA, Macoir et al., 2017) and F (MoCA, Nasreddine et al., 2005)) was also administered, with the total number of words for the two letters as an index of mental flexibility. Finally, working memory was assessed with the Digit Span subtest (forward and backward) from the WAIS-III (Wechsler, 1981) and the French version of the Reading Span Test (RST; Desmette et al., 1995). For each test, the longest series of numbers and words recalled were used as a measure of working memory.

Theory of mind. A short version of the Faux Pas test (Mini-SEA (Social cognition \& Emotional Assessment), Bertoux, 2014) was used to assess ToM abilities. The participants had to read 10 shorts stories, half of which containing a social faux pas. After each story, the participants had to determine if a character had said something that he/she should not have said. In the faux pas stories, the participants subsequently had to infer the unintentionality of the faux pas and the possible hurtfulness for the listener. In the control stories, no faux pas was committed. After all the stories, non-ToM based memory questions were asked to assess the participants' story comprehension. Three scores were calculated: the faux pas stories (/ 30), control stories (/ 10) and total (/40) scores.

Experimental paradigm. Irony comprehension. An irony comprehension task was purpose-designed to explore the influence of context integration, EF, and ToM in the 
Running head: Heterogeneity of neuropsychological and pragmatics profiles

comprehension of irony. The irony comprehension task consisted of 18 brief scenarios, inspired by Spotorno et al. (2012) and Champagne-Lavau et al. (2012). Each story depicted an interaction between two characters of different gender and ended with a statement that could be interpreted literally or ironically depending on the context preceding the statement. After each story, the participants had to answer two questions: a question on the speaker's intent ("What does X (the speaker) mean?") and a control question on contextual information (see figure 1).

Each story was controlled in terms of structure and length. The first two sentences introduced the two characters. The third sentence introduced the contextual element, positive or negative, that induced the literal or ironic interpretation. A fourth neutral sentence was followed by the final utterance of the speaker. The stories were $70-80$ words long and ended with a 5-8 words utterance, which was stated fifty percent of the time by a male speaker.

To evaluate to what extent the subjects were sensitive to the context and cognitive resources, six story conditions were created by manipulating three factors: 1) the context (inducing a literal or ironic meaning), 2) the EF demand of the stories (low or high) and 3) the markers of irony (no or with) cueing a speaker ironic intent (see figure 1).

As previously mentioned, the context was manipulated in the third sentence of the story to induce a literal, or an ironic meaning: In the literal conditions, the target sentence (e.g., "The meal tonight will be hearty") was always preceded by a positive context (e.g., fruitful fishing) whereas in the ironic conditions in the target sentence, it was preceded by a negative context (e.g., unsuccessful fishing).

The EF demand of half of the stories was manipulated by adding a 4-sentences distractor paragraph, introducing a new character and irrelevant information for the interpretation of the target sentence. By bringing some noise and increasing the distance between the relevant contextual element (third sentence) and the target sentence, this supplementary paragraph 
Running head: Heterogeneity of neuropsychological and pragmatics profiles

increased the load on inhibition, flexibility, and working memory. It was absent in the (literal and ironic) conditions with low EF demand but was added to the (literal and ironic) conditions with high EF demand.

Finally, in the ironic conditions (with both low and high EF demand), the stories were manipulated in terms of presence or absence of marker of irony. In the ironic conditions with markers (with low or high EF demand), an occupation stereotype cueing ironic intent was associated to the ironic character, while a lexical term of exaggeration was added to the target sentence. These markers were absent in the ironic conditions with no marker (with low or high EF demand).

In summary, each story was derived from 6 conditions:

- Literal with low EF demand,

- Literal with high EF demand,

- Ironic with low EF demand and no marker of irony,

- Ironic with high EF demand and no marker of irony,

- Ironic with low EF demand and markers of irony,

- Ironic with high EF demand and markers of irony.

\section{INSERT FIGURE 1}

Given the number of stories (18 stories x 6 conditions), three groups of items, each comprising one third of the stories (6 of each condition), were created according to a Latin square design. Each $\mathrm{ABI}$ and $\mathrm{HC}$ participant was then randomly assigned to one of the three 
Running head: Heterogeneity of neuropsychological and pragmatics profiles

groups. ${ }^{1}$ To control prosody and memory effect, stimuli were presented one at a time in a fixed randomized order on a single screen and were left on display during the questions answers.

Scoring. Verbal answers to questions on each speaker's intent were audio-recorded and transcribed. A binary scoring system was developed based on pilot data. In the literal conditions, 1 point was given for a correct paraphrase of the statement. In the ironic conditions, the participants were expected to mention an ironic intention, i.e. a meaning which opposed or was different to the target utterance or a correct function of irony (e.g., he is mocking the character) to score 1 point. Any other answer was rated 0 . The errors were then classified according to five categories: "incorrect ironic response" (in literal conditions), "incorrect literal response" (in the ironic conditions), "incorrect non-literal response" (e.g., the character is flirting / is telling lies / doesn't want to hurt), "no response” (e.g., I don't know) and "other" (off topic answers).

Answers to each control question were also scored 1 if correct and 0 if incorrect. Half of the correct answers were "yes" while the other half were "no". All data were scored by the first author (NC) and a random sample of the data (20\% of the data, 792 responses) was scored by a research assistant who was blind to the type of participants tested. The inter-rater reliability was $96.59 \%$ with a Cohen's Kappa $\mathrm{K}=.828 ; p<.0001$, showing a strong interrater reliability. All differences were resolved by discussion.

Validation of the material. Two pilot studies were conducted to validate the material. The purpose of the first pilot study was to ensure a good understanding of the ironic or literal intention of the statements in the 20 stories built. Forty-two undergraduate students (mean age: 19.86, SD: 1.68) from the University of Neuchâtel and Geneva (Switzerland) were 
Running head: Heterogeneity of neuropsychological and pragmatics profiles

recruited. For each story, they were asked to judge if the final statement was sincere or sarcastic (with an "I don't know" answer available). The eighteen stories with the highest success score were retained (mean percentage of success: $97.55 \%$, SD: 2.87).

The second pilot study, using the Pexman and Olineck (2002) procedure, was conducted to identify the occupation stereotypes cueing the speaker's ironic intent. This occupation stereotype then had to be incorporated into the stories in the ironic conditions with markers of irony. Fifty undergraduate students (mean age: 22.48, SD: 3.01) from the University of Neuchâtel were recruited. They were asked to rate the likelihood that people with different occupations would make an ironic remark in a given situation (flat tire on the way to work) using a 5 -point scale ( $1=$ low probability, $5=$ high probability). Of the eighty occupations tested in that pilot study, the following ten occupations were judged as having the highest probability ( $\mathrm{p}>3.3$ ) of ironic remarks ("sarcastic occupations"): radio host, TV show host, comedian, mechanic, film director, driving instructor, journalist, holiday club host, film critic and lawyer (mean: 3.65, SD: 0.31). Results of a paired t-test showed that the average judgment of the ten occupations selected differed significantly from the midpoint of the Likert scale (i.e., 3) $(t(9)=6.69, p<.0001)$. Similarly, an independent t-test analysis revealed that the average judgment of the ten occupations selected was significantly higher than the average judgment of the seventy occupations non selected $(t(78)=8.97, p<.0001)$.

\section{Data analyses}

Unpaired $t$-tests were used to explore group differences on the neuropsychological data. To examine differences between groups in the irony task, 2 repeated measures analyses of variance (ANOVAs) were performed. First, a 2 group (ABI, HC) x 2 context (Literal, Ironic) x 2 EF demand (Low, High) repeated measures ANOVA was performed on the mean of correct responses to the question on the speaker's intent and the control question. As the 
Running head: Heterogeneity of neuropsychological and pragmatics profiles

factor markers of irony was not manipulated in the literal conditions, only ironic conditions with no marker of irony were considered in this analysis. Secondly, a 2 group (ABI, HC) x 2 markers of irony (No, With) x 2 EF demand (Low, High) repeated measures ANOVA was performed on the mean of correct responses to the question on the speaker's intent and the control question for the ironic conditions. These analyses were also performed with age as a co-variable (ANCOVAs). The results showed no main effect of age or significant interaction with the age factor, and are thus not reported below.

To account for the heterogeneity of patients regarding irony comprehension, a hierarchical cluster analysis using the Ward's method (Ward, 1963) was then undertaken. This analysis was based on the ABI individuals' responses to the speaker's intent questions in the six conditions. Using the Ward's method results to classify our ABI participants into several subgroups according to their performance under the different conditions of the task. Participants with similar performances were thus grouped together in the same subgroup. Grouping clusters leads to the minimum increase in total within-cluster variance. This agglomerative method has thus, the advantage of minimizing the increase in total withincluster sum of squared error, which is proportional to the Euclidean distance squared between the centers of the clusters. Non-parametric analyses were then performed to characterize the different profiles obtained. Following these analyses, the different subgroups were named a posteriori according to the problematic condition(s) evidenced.

Measures of effect sizes were also calculated for each effect of interest by providing the partial eta-squared for ANOVAs and the Cohen's $d$ for t-tests. The effect size was small if its value was between 0.01 and 0.05 , moderate between 0.06 and 0.13 , and large above 0.14 for the partial eta-squared. For the Cohen's $d$, the effect size was small between 0.2 and 0.4 , moderate between 0.5 and 0.7 , and large above 0.8 . Given multiple testing, the alpha level was adjusted with the false discovery rate (FDR) method using the Benjamini-Hochberg 
Running head: Heterogeneity of neuropsychological and pragmatics profiles

procedure. After this correction, the threshold of significance was set at $p<.019$ for all the analyses. Statistical analyses were conducted using IBM SPSS Version 25.

\section{Results}

\section{Group comparison on neuropsychological measures}

The neuropsychological characteristics of both groups are detailed in Table 2. The ABI group performed more poorly than the control group on the MoCA score and several executive functions measures, especially verbal inhibition (Hayling) and working memory (Digit SPAN backward). They also had a lower performance on theory of mind (Mini-SEA total score and faux pas score).

\section{INSERT TABLE 2}

\section{Group comparison on irony comprehension}

\section{Irony with no marker versus literal.}

Questions on the speaker's intent: The ironic conditions (with low and high EF demand) were initially compared with the literal conditions (with low and high EF demand) for the two groups. The 2 group (ABI, HC) x 2 context (Literal, Ironic) x 2 EF demand (Low, High) repeated measures ANOVA on the number of correct responses to the question on the speaker's intent showed a main effect of group $\left(F(1,58)=7.99, p<.007 ; \eta_{\mathrm{p}}{ }^{2}=.121\right)$, with the ABI participants having a significantly worse performance than the $\mathrm{HC}$ participants. There 
Running head: Heterogeneity of neuropsychological and pragmatics profiles

was also a main effect of context $\left(F(1,58)=10.98, p<.002 ; \eta_{\mathrm{p}}^{2}=.159\right)$, with poorer

performance in the ironic conditions with no marker of irony than in the literal conditions. A main effect of the EF demand was found $\left(F(1,58)=38.69, p<.0001 ; \eta_{\mathrm{p}}{ }^{2}=.4\right)$, with more errors in the high EF demand conditions than in the low EF demand conditions. The results also showed a significant group x EF demand interaction $\left(F(1,58)=16.66, p<.0002 ; \eta_{\mathrm{p}}{ }^{2}\right.$ $=.223$ ). This interaction was broken down according to group. The ABI group made more errors in the high EF demand conditions than in the low EF demand conditions $(p<.0001)$ while this difference did not exist in the HC group $(p>.05)$. No further interactions were significant (see Table 3).

Control questions: the $2 \times 2 \times 2$ repeated measures ANOVA revealed a main effect of group $\left(F(1,58)=12.10, p<.001 ; \eta_{\mathrm{p}}^{2}=.173\right)$, meaning that the ABI participants made more errors than the HC participants. There was no main effect of context $(F(1,58)=0.15, p>.05)$ and no main effect of EF demand $(F(1,58)=2.59, p>.05)$. No interactions were significant (see Table 3).

\section{Irony with and without markers}

Questions on the speaker's intent: The ABI and healthy control groups were then compared, with regard to the ironic conditions with and with no markers of irony (with low and high EF demand). The 2 group (ABI, HC) x 2 markers of irony (No, With) x 2 EF demand (Low, High) repeated measures ANOVA on the number of correct responses to the question on the speaker's intent showed a main effect of EF demand $(F(1,58)=48.26, p$ $\left.<.0001 ; \eta_{\mathrm{p}}{ }^{2}=.454\right)$, with poorer performance in the high EF demand conditions than in the low EF demand conditions. There was no main effect of group $(F(1,58)=4.81, p<.033)$ and no main effect of markers of irony $(F(1,58)=5.01, p<.03)$. Group x markers of irony $(F(1,58)=0.97, p>.05)$, group $\mathrm{x} \mathrm{EF}$ demand $(F(1,58)=5.36, p<.025)$ and markers of irony 
Running head: Heterogeneity of neuropsychological and pragmatics profiles

$\mathrm{x}$ EF demand $(F(1,58)=3.71, p>.05)$ interactions were not significant. The group $\mathrm{x}$ markers of irony $\mathrm{x}$ EF demand interaction was significant $\left(F(1,58)=7.63, p<.008 ; \eta_{\mathrm{p}}{ }^{2}=.116\right)$. This interaction was broken down according to group. In the high EF demand conditions, the ABI group made more errors in the ironic stories with no marker of irony than in the ironic stories with markers of irony $(p<.002)$. In the low EF demand conditions, there was no difference between the ironic stories with or with no markers of irony for that group $(p>.05)$. In the HC group, there was no difference between the ironic stories with no marker of irony and the ironic stories with markers of irony, either in the high EF demand condition $(p>.05)$ or in the low EF demand condition $(p>.05)$ (see Table 3).

Control questions: the $2 \times 2 \times 2$ ANOVA revealed a main effect of EF demand $(F(1,58)=$ $7.24, p<.01 ; \eta_{\mathrm{p}}^{2}=.111$ ), with a poorer performance in the high EF demand conditions than in the low EF demand conditions. There was no main effect of group $(F(1,58)=5.54, p>.05)$ and no main effect of markers of irony $(F(1,58)=0.43, p>.05)$. The group $\mathrm{x}$ EF demand interaction was significant $\left(F(1,58)=10.11, p<.003 ; \eta_{\mathrm{p}}^{2}=.148\right)$. The ABI participants made more errors in the high EF demand conditions than in the low EF demand conditions ( $p$ $<.0001)$ while such a difference did not exist in the HC group $(p>.05)$. No further interactions were significant (see Table 3).

Overall, these results suggest that the ABI participants made more errors than the HC participants in answering questions on the speaker's intent, especially in the conditions of high EF demand. Unlike the HC participants, they performed more poorly in ironic stories with no marker of irony than in ironic stories with markers of irony in high EF demand conditions. They also performed more poorly in answering control questions in the high EF demand conditions, although their scores remained high. 
Running head: Heterogeneity of neuropsychological and pragmatics profiles

INSERT TABLE 3

\section{Different patterns of $\mathrm{ABI}$ performances}

The hierarchical cluster analysis undertaken according to ABI performance on the questions on the speaker's intent in the six conditions revealed four clusters (see Figure 2) suggesting four patterns of performance. These four subgroups were named a posteriori according to the problematic condition(s) evidenced on the non-parametric analyses: ABI - U (Unimpaired on ironic evaluation), ABI - LH (impaired in the Literal condition with High EF demand), ABI - INH (impaired in the Ironic condition with No marker of irony and High EF demand) and ABI - I (impaired in all the Ironic conditions).

\section{INSERT FIGURE 2}

Due to the small number of participants in each subgroup, non-parametric tests (KruskalWallis) were conducted to explore differences between the five groups (HC, ABI-U, ABI-LH, ABI-INH and ABI-I) with regard to age, educational level, time post-onset, neuropsychological data and the irony task. A post hoc Mann-Whitney test was performed when a difference was found in the Kruskal-Wallis analyses between the neuropsychological variables and the irony task. For the sake of clarity, only the significant results of the post hoc Mann-Whitney tests obtained in each subgroup are presented below. 
Running head: Heterogeneity of neuropsychological and pragmatics profiles

Kruskal analyses performed on sociodemographic and neuropsychological data revealed significant differences between groups on measures of working memory (Digit Span backward), verbal inhibition (Hayling) and theory of mind (Mini-SEA total score and faux pas score). Means, standard deviations and p-values for sociodemographic variables and neuropsychological tests are available in Table 4.

\section{INSERT TABLE 4}

The results of each subgroup in every condition of the irony task for the questions on the speaker's intent and the control questions are shown in Table 5. The Kruskal-Wallis analysis performed on the correct responses to the questions on the speaker's intent for each condition revealed significant group differences in all the conditions, except for the literal condition with low EF demand.

For the correct responses to the control questions, the Kruskal-Wallis analysis revealed significant differences between the subgroups only in the ironic condition with no marker of irony and high EF demand. The other differences were not significant.

\section{INSERT TABLE 5}

Analyses of the results of the post hoc Mann-Whitney test revealed four profiles, characterized by distinct pragmatic and neuropsychological patterns. 
Running head: Heterogeneity of neuropsychological and pragmatics profiles

Participants Unimpaired on ironic evaluation (ABI-U profile; 7 TBI, 3 RHD) represent $33 \%$ of the ABI participants, who performed similarly to HC participants on the irony, executive and ToM tasks. They made only seven errors (out of 360 answers), mostly incorrect and non-literal, when answering the questions on the speaker's intent.

Participants Impaired in the Literal condition with High EF demand (ABI-LH profile; 4 TBI, 5 RHD): Thirty percent of the ABI participants, characterized by an inhibition deficit (Hayling inh: $U=57.50, p<.009$ ), showed difficulties in interpreting literal statements in the high EF demand condition $(U=16, p<.0001)$. Their 34 errors $(/ 324$ responses) were essentially incorrect ironic responses $(30 \%)$ in the literal conditions and incorrect non-literal responses (30\%; e.g.: The character is flirting/ is telling lies) in the ironic conditions.

\section{Participants Impaired in the Ironic condition with No marker of irony and High EF} demand (ABI-INH profile; 3 TBI, 3 RHD): Twenty percent of our participants exhibited a co-occurrence of working memory (Digit SPAN backward: $U=34, p<.016$ ) and Inhibition (Hayling inh: $U=18.50, p<.002$ ) deficits with difficulties in answering the questions on the speaker's intent $(U=12.50, p<.0001)$ and the control questions $(U=33, p<.014)$ in the ironic conditions with no marker of irony and a high EF demand. They made 28 errors (/216 answers) when answering the questions on the speaker's intent: forty-three percent of the errors were classified as incorrect non-literal responses and thirty-two percent as incorrect literal responses.

Participants impaired in all the Ironic conditions (ABI- I profile; 3 TBI, 2 RHD): 17\% of our participants had poorer performance than the HC group when answering the questions on the speaker's intent in all the ironic conditions: ironic conditions with no marker of irony and low EF demand $(U=25, p<.017)$ or high EF demand $(U=1, p<.0001)$, and ironic conditions with markers of irony and low EF demand $(U=0, p<.0001)$ or high EF demand $(U=6, p<.0001)$. Out of the 71 errors $(/ 180$ answers $)$, the majority of the errors $(55 \%)$ were 
Running head: Heterogeneity of neuropsychological and pragmatics profiles

incorrect literal interpretations, while thirty-three percent of the errors were incorrect nonliteral responses. This pattern of pragmatic performance co-occurred with worse performance on inhibition (Hayling inh: $U=2.50, p<.0001$; Hayling auto: $U=24, p<.014$ ), working memory (Digit SPAN backward: $U=22, p<.01$ ) and theory of mind (Mini-SEA total: $U=$ 5.50, $p<.001$; Mini-SEA faux pas: $U=5, p<.001)$.

\section{Discussion}

The present study aimed to further explore the underlying mechanisms of ironic understanding disorders (i.e. context processing, EF, and ToM) in ABI patients. To this aim, we created the first irony task in which context, EF demand, and ToM were manipulated. The EF demand in the literal and ironic stories was manipulated by adding (high EF demand) or not (low EF demand) a distractor paragraph introducing irrelevant information for the interpretation of the target sentence. In the ironic conditions (with low and high EF demand), the stories were manipulated in terms of presence or absence of markers inducing irony. Finally, the presence of ironic and literal conditions enabled us to evaluate the ToM through a question about the intention of the speaker ("What does X mean?") which was asked at the end of each story. We administered this task and classical neuropsychological tests assessing working memory, flexibility, inhibition and ToM to $30 \mathrm{ABI}$ and $30 \mathrm{HC}$ participants.

The main results showed that the ABI group made more errors than the HC group in answering questions about the literal or ironic intent of target statements, especially when the EF demand was high and in the absence of markers of irony. Given the heterogeneity of neuropathology and disorders following a brain injury, we conducted a cluster analysis to identify the inter-individual differences possibly masked by the group analysis. This analysis pointed out that while one subgroup (ABI-U) did not differ from the HC group, the three other 
Running head: Heterogeneity of neuropsychological and pragmatics profiles

subgroups (ABI-LH, ABI-INH, ABI-I) showed different neuropsychological and pragmatic patterns of performance. Such results confirmed the known heterogeneity and difficulties in understanding irony in ABI participants (Blake et al., 2002; Bosco et al., 2018; ChampagneLavau et al., 2018; Champagne-Lavau \& Joanette, 2009; Channon et al., 2005; Winner et al., 1998). These profiles did not differ in socio-demographic measures. On the contrary, the ability to process the context as well as the executive and ToM deficits seem to account for the different pragmatic profiles observed in the ABI participants.

The ability to process the context differed according to our groups. Indeed, one subgroup (ABI-I - impaired in all the Ironic conditions) exhibited a poor performance when answering the questions on the speaker's intent in all ironic conditions, regardless of the presence of markers of irony, with many incorrect literal interpretations of ironic utterances. This expected pattern of performance strengthens previous results showing that some $\mathrm{ABI}$ individuals might be insensitive to context and would process the ironic statements locally (e.g RHD-I subgroup in Champagne-Lavau et al., 2018; Cornejo et al., 2007; Kaplan et al., 1990). Two subgroups (ABI-U - Unimpaired on ironic evaluation and ABI-LH - impaired in the Literal condition with High EF demand) succeeded in all the ironic conditions (with and without markers of irony). These findings confirm that such markers (occupation stereotype cueing ironic intent and lexical term of exaggeration) are not necessary for the comprehension of irony (Attardo, 2000) since these ABI participants performed well in ironic stories with and without markers of irony. On the other hand, our results are in line with previous studies showing that ABI patients are able to make inferences when the context was sufficiently strong (Blake, 2009; McDonald \& Flanagan, 2004). Indeed, one subgroup (ABI-INH - impaired in the Ironic condition with No marker of irony and High EF demand) made more errors than HC participants when answering the questions on the speaker's intent in ironic condition with no marker of irony and high EF demand but performed well in conditions with markers of irony 
Running head: Heterogeneity of neuropsychological and pragmatics profiles

whatever the EF demand. Our study is, however, the first to suggest that markers of irony, such as occupation stereotype and lexical term of exaggeration, could help some ABI patients understand irony despite the impact of EF demand, as we will discuss below.

A second significant result suggests a potential account for certain EF in the comprehension of irony. As expected, the three subgroups with pragmatic impairments (ABILH, ABI-INH, and ABI-I) exhibited inhibition deficits measured by the Hayling test. The preponderant role of inhibition in the comprehension of irony is consistent with prior literature (Champagne et al., 2004; Champagne-Lavau et Joanette, 2009; Channon \& Crawford, 2010; Channon \& Watts, 2003; McDonald et al., 2014). In the same way, the absence of flexibility disorders in our different subgroups supports the controversial role of flexibility in pragmatics abilities (McDonald, 2000; Champagne et al., 2004; Martin et McDonald, 2005; McDonald et al. 2006, 2017; Shamay-Tsoory et al., 2005).

A new finding concerns the influence of increased EF demand on the understanding of irony. Two subgroups (ABI-LH - impaired in the Literal condition with High EF demand and ABI-INH - impaired in the Ironic condition with No marker of irony and High EF demand) exhibited pragmatic impairments only in conditions with high EF demand. These results support earlier studies that found an impact of cognitive task demand on discourse (Byom and Turkstra, 2017, McDonald et al., 2014), understanding of metaphors (Prat, Mason \& Just, 2012), and ToM capacities (Honan et al., 2015) in TBI, RHD, and HC individuals. In our irony task, the addition of a distracting paragraph increased the gap between relevant information (e.g., the contextual incongruity) and the target statement. The resources in working memory were consequently more demanded. Just \& Carpenter (1992) suggested that performance deterioration in language processing would be observed in tasks exceeding the limited resources in working memory. Tompkins, Bloise, Timko \& Baumgaertner (1994) thus 
Running head: Heterogeneity of neuropsychological and pragmatics profiles

demonstrated a significant correlation between working memory measures and the ability to solve incongruous and congruent attitudinal inferences in RHD individuals. Comprehension of irony is a complex process requiring the detection and repair of incongruity. Adding a distractor paragraph in ironic stories further increased the demand for working memory. We may presume that ironic conditions with a distractor paragraph require more working memory resources than those available to our ABI-INH participants, as confirmed by their performance at the Digit Span backward. This insufficiency resulted in significant difficulties in answering questions on the speaker's intent in the ironic with high EF demand condition. The significant, albeit minimal, error rate in the factual control questions (mean: 5.3 / 6) may also reflect the impact of the stories' length with high EF demand. These difficulties, however, were not apparent in the ironic condition with high EF demand when markers of irony were present. In this condition, an occupation stereotype was associated with the ironic character at the beginning of the story and before the target statement, and a lexical term of exaggeration was added to the target statement. These markers of irony, being placed just before the target statement, could thus decrease the load in working memory by helping to infer the ironic intention of the character at the end of the story. It would be interesting in future research to identify the nature and the number of indices contributing to the understanding of irony in ABI participants since their influence has been suggested in several studies (Blake, 2010; Kaplan et al., 1990).

Similarly, we can assume that adding a distractor paragraph requiring a high level of working memory is likely to have exacerbated ToM impairments in the ABI-LH subgroup (impaired in the Literal condition with High EF demand), as suggested by Honan et al. (2015). However, the novelty of this study lies in the analysis of errors in the question on the speaker's intent, enabling a more detailed analysis of the ToM profiles of our participants. Abu-Akel (2003) suggested that ToM disorders could be represented as a continuum ranging 
Running head: Heterogeneity of neuropsychological and pragmatics profiles

from (1) an absence of understanding of the mental states of others to (2) a good understanding of mental states but a poor ability to apply them until (3) an intact understanding of the mind of others but a deterioration in understanding of his own mind. By their large proportion of incorrect ironic responses in the literal with high EF demand condition, the ABI-LH group appears to present the second type of ToM disorder, characterized by an over-attribution of intentions (Abu-Akel, 2003; Champagne-Lavau \& Joanette, 2009). Instead, the pattern of performance of the ABI-I subgroup seems to correspond to the first type: They tended to respond literally to questions about the speaker's intent in the ironic conditions, regardless of the EF demand and had a worse performance in the faux pas test. This latter subgroup also had significant EF deficits, confirming that a joint deficit of ToM and EF is generally associated with the most severe pragmatic disorders (Bosco et al., 2017; Byom \& Turkstra, 2017; Champagne-Lavau \& Joanette, 2009; Honan et al., 2015; McDonald et al., 2014).

These results have important clinical implications. They highlight the importance of considering the cognitive demand of the tasks used to assess pragmatic disorders. This cognitive demand must be considered both in the structure of the stimuli and the format of the tasks used. The results of McDonald and Saunders (2005) suggest that audiovisual tasks, although more ecological, increase the amount of information to be processed and, therefore, the difficulties manifested by ABI patients. The heterogeneity of the performances reported in this study must also be considered for therapies. Indeed, it is essential to identify the underlying deficit that may explain the difficulties to propose tailored and personalized treatments (Blake 2007; Channon and Crawford 2010; Tompkins 2012). Several therapies based on the supposed underlying causes - suppression deficits, ToM, FE, and cognitive resources - have been advanced (Blake, 2007; Tompkins, 2012). The task developed in this 
Running head: Heterogeneity of neuropsychological and pragmatics profiles

study, by allowing the identification of distinct profiles, thus seems promising for the development of future therapies.

Several limitations of the present study need to be addressed. Firstly, the sample size of 30 participants, although consistent with experimental studies involving brain-injured individuals, was relatively small. Once the cluster analysis completed, subgroups contained a tiny number of individuals. If the generalization to other patients may prove to be limited, it is essential to note that these profiles confirm different results highlighted in the literature. Furthermore, it would be interesting to replicate the present study with other EF tests in order to confirm our results. Finally, the lack of information on neuropathology did not enable us to identify the impact of brain damage on pragmatic performance.

To conclude, this study is the first to use a paradigm manipulating the mechanisms underlying ironic comprehension disorders (i.e., context integration, ToM, and EF) within an irony task. This paradigm allowed us to shed new light on these mechanisms, which proves to be of some importance. Our results confirmed the role of inhibition in the comprehension of irony and clarified the impact of working memory impairment on understanding more cognitively-complex ironic stories. The presence of markers of irony, such as speaker stereotypes and lexical markers, might help some ABI patients bypass the cognitive load effect. Our results also showed that the association of executive and ToM disorders might lead to the most severe pragmatic diseases, characterized by insensitivity to context and literal interpretations of ironic statements. The various impairments of these mechanisms might account, at least in part, for the heterogeneity of the irony comprehension disorders observed in $\mathrm{ABI}$ individuals. 
Running head: Heterogeneity of neuropsychological and pragmatics profiles

\section{References}

Abu-Akel, A. (2003). A neurobiological mapping of theory of mind. Brain research reviews, 43(1), 29-40. doi: 10.1016 /S0165-0173(03)00190-5

Attardo, S. (2000). Irony markers and functions: Towards a goal-oriented theory of irony and its processing. Rask, 12(1), 3-20.

Bertoux, M. L. (2014). Mini SEA: Évaluation de la démence fronto-temporale. De Boeck Superieur.

Bettcher, B. M., Mungas, D., Patel, N., Elofson, J., Dutt, S., Wynn, M., ... \& Kramer, J. H. (2016). Neuroanatomical substrates of executive functions: beyond prefrontal structures. Neuropsychologia, 85, 100-109. doi: 10.1016/j.neuropsychologia.2016.03.001.

Blake, M. L. (2007). Perspectives on treatment for communication deficits associated with right hemisphere brain damage. American Journal of Speech-Language Pathology, 16 (4), 331-342. doi: 10.1044/1058-0360(2007/037)

Blake, M. L. (2009). Inferencing processes after right hemisphere brain damage: Effects of contextual bias. Journal of Speech, Language, and Hearing Research, 52(2), 373-384. doi: 10.1044/1092-4388(2009/07-0172).

Blake, M. L. (2010). Communication deficits associated with right hemisphere brain damage. In J. S. Damico, N. Muller, \& M. J. Ball (Eds.), The handbook of language and speech disorders (pp. 556-576). Chichester, W Sussex: Wiley-Blackwell. 
Running head: Heterogeneity of neuropsychological and pragmatics profiles

Blake, M. L. (2017). Right-hemisphere pragmatic disorders. In L. Cummings (Ed.), Research in clinical pragmatics (pp. 243-266). Cham, Switzerland: Springer International.

Blake, M. L., Duffy, J. R., Myers, P. S., \& Tompkins, C. A. (2002). Prevalence and patterns of right hemisphere cognitive/communicative deficits: Retrospective data from an inpatient rehabilitation unit. Aphasiology, 16(4-6), 537-547. doi: 10.1080/02687030244000194

Bosco, F. M., Gabbatore, I., Angeleri, R., Zettin, M., \& Parola, A. (2018). Do executive function and theory of mind predict pragmatic abilities following traumatic brain injury? An analysis of sincere, deceitful and ironic communicative acts. Journal of communication disorders, 75, 102-117. doi: https://doi.org/10.1016/j.jcomdis.2018.05.002

Bosco, F. M., Parola, A., Sacco, K., Zettin, M., \& Angeleri, R. (2017). Communicativepragmatic disorders in traumatic brain injury: The role of theory of mind and executive functions. Brain and language, 168, 73-83.

doi:http://dx.doi.org/10.1016/j.bandl.2017.01.007

Byom, L., \& Turkstra, L. S. (2017). Cognitive task demands and discourse performance after traumatic brain injury. International journal of language \& communication disorders, 52(4), 501-513. doi: 10.1111/1460-6984.12289.

Champagne, M., Desautels, M. C., \& Joanette, Y. (2004). Lack of inhibition could contribute to non-literal language impairments in right-hemisphere-damaged individuals. Brain and Language, 91(1), 172-174. doi: 10.1016/j.bandl.2004.06.089 
Running head: Heterogeneity of neuropsychological and pragmatics profiles

Champagne-Lavau, M., Cordonier, N., Bellmann, A., \& Fossard, M. (2018). Context processing during irony comprehension in right-frontal brain-damaged individuals. Clinical linguistics \& phonetics, 32(8), 721-738. doi: 10.1080/02699206.2018.1430851

Champagne-Lavau, M., \& Joanette, Y. (2009). Pragmatics, theory of mind and executive functions after a right-hemisphere lesion: Different patterns of deficits. Journal of neurolinguistics, 22(5), 413-426. doi: 10.1016/j.jneuroling.2009.02.002

Channon, S., \& Crawford, S. (2010). Mentalising and social problem-solving after brain injury. Neuropsychological Rehabilitation, 20(5), 739-759.

doi:10.1080/09602011003794583

Channon, S., Pellijeff, A., \& Rule, A. (2005). Social cognition after head injury: Sarcasm and theory of mind. Brain and Language, 93, 123-134. doi: 10.1016/j.band1.2004.09.002

Channon, S., \& Watts, M. (2003). Pragmatic language interpretation after closed head injury: Relationship to executive functioning. Cognitive Neuropsychiatry, 8(4), 243-260. doi:10.1080/135468000344000002

Cornejo, C., Simonetti, F., Aldunate, N., Ibáñez, A., López, V., \& Melloni, L. (2007). Electrophysiological evidence of different interpretative strategies in irony comprehension. Journal of psycholinguistic research, 36(6), 411-430. doi: 10.1007/s10936-007-9052-0 
Running head: Heterogeneity of neuropsychological and pragmatics profiles

Côté, H., Payer, M., Giroux, F., \& Joanette, Y. (2007). Towards a description of clinical communication impairment profiles following right-hemisphere damage. Aphasiology, 21(6-8), 739-749. doi: 10.1080/02687030701192331

Dahlberg, C., Hawley, L., Morey, C., Newman, J., Cusick, C. P., \& Harrison-Felix, C. (2006). Social communication skills in persons with post-acute traumatic brain injury: Three perspectives. Brain Injury, 20(4), 425-435. doi: 10.1080/02699050600664574

Dardier, V., Bernicot, J., Delanoë, A., Vanberten, M., Fayada, C., Chevignard, M., ... \& Dubois, B. (2011). Severe traumatic brain injury, frontal lesions, and social aspects of language use: A study of French-speaking adults. Journal of Communication Disorders, 44(3), 359-378. doi:10.1016/j.jcomdis.2011.02.001

Dews, S., \& Winner, E. (1997). Attributing meaning to deliberately false utterances: The case of irony. In C. Mandell \& A. McCabe (Eds.), The problem of meaning: Behavioral and cognitive perspectives (pp. 377-414). New York: Elsevier Science..

Eviatar, Z. \& Just, M.A. (2006). Brain correlates of discourse processing: an fMRI investigation of irony and conventional metaphor comprehension. Neuropsychologia 44, 2348-2359. doi: 10.1016/j.neuropsychologia.2006.05.007

Gibbs, R. W. (1986). On the psycholinguistics of sarcasm. Journal of Experimental Psychology-General, 115(1), 3-15. doi: https://doi.org/10.1037/0096-3445.115.1.3 
Running head: Heterogeneity of neuropsychological and pragmatics profiles

Gibbs, R. W. (2000). Irony in talk among friends. Metaphor and symbol,15(1-2), 5-27. doi: $10.1080 / 10926488.2000 .9678862$

Grice, P. (1957). Meaning. The Philosophical Review, 66, 377-388. doi: 10.2307/2182440

Heaton, R. K. (1981). Wisconsin Card Sorting Test: Manual. Odessa, FL: Neuropsychological Assessment Resources.

Hofgren, C., Esbjörnsson, E., \& Sunnerhagen, K. S. (2010). Return to work after acquired brain injury: facilitators and hindrances observed in a sub-acute rehabilitation setting. Work, 36(4), 431-439. doi: 10.3233/WOR20101039

Honan, C. A., McDonald, S., Gowland, A., Fisher, A., \& Randall, R. K. (2015). Deficits in comprehension of speech acts after TBI: The role of theory of mind and executive function. Brain and Language, 150, 69-79. doi: http://dx.doi.org/10.1016/j.band1.2015.08.007

Ivanko, S. L., \& Pexman, P. M. (2003). Context incongruity and irony processing. Discourse Processes, 35(3), 241-279. doi: 10.1207/S15326950DP3503_2

Just, M. A., \& Carpenter, P. A. (1992). A capacity theory of comprehension: individual differences in working memory. Psychological review, 99(1), 122-149. doi: https://doi.org/10.1037/0033-295X.99.1.122 
Running head: Heterogeneity of neuropsychological and pragmatics profiles

Kaplan, J. A., Brownell, H. H., Jacobs, J. R., \& Gardner, H. (1990). The effects of right hemisphere damage on the pragmatic interpretation of conversational remarks. Brain and Language, 38(2), 315-333. doi: https://doi.org/10.1016/0093-934X(90)90117-Y

Kreuz, R. J., \& Glucksberg, S. (1989). How to be sarcastic: The echoic reminder theory of verbal irony. Journal of experimental psychology: General, 118(4), 374-386. doi:https://doi.org/10.1037/0096-3445.118.4.374

Kreuz, R. J., \& Roberts, R. M. (1995). Two cues for verbal irony: Hyperbole and the ironic tone of voice. Metaphor and symbol, 10(1), 21-31.doi: 10.1207/s15327868ms1001_3

Lundgren, K., \& Brownell, H. (2016). Figurative language deficits associated with right hemisphere disorder. Perspectives of the ASHA Special Interest Groups, 1(2), 66-81. doi:10.1044/persp1.SIG2.66

Macoir, J., Fossard, M., Lefebvre, L., Monetta, L., Renard, A., Tran, T. M., \& Wilson, M. A. (2017). Detection Test for Language Impairments in Adults and the Aged—a new screening test for language impairment associated with neurodegenerative diseases: validation and normative data. American Journal of Alzheimer's Disease \& Other Dementias ${ }^{\circledR}, 32(7), 382-392$.

Martin, I., \& McDonald, S. (2003). Weak coherence, no theory of mind, or executive dysfunction? Solving the puzzle of pragmatic language disorders. Brain and Language, 85, 451-466. doi:10.1016/S0093-934X(03)00070-1 
Running head: Heterogeneity of neuropsychological and pragmatics profiles

Martin, I., \& McDonald, S. (2005). Evaluating the causes of impaired irony comprehension following traumatic brain injury. Aphasiology, 19, 712-730.

doi:10.1080/02687030500172203

Martín-Rodríguez, J. F., \& León-Carrión, J. (2010). Theory of mind deficits in patients with acquired brain injury: A quantitative review. Neuropsychologia, 48(5), 1181-1191.

doi:10.1016/j.neuropsychologia.2010.02.009

Maas, A. I., Stocchetti, N., \& Bullock, R. (2008). Moderate and severe traumatic brain injury in adults. The Lancet Neurology, 7(8), 728-741.

McDonald, B. C., Flashman, L. A., \& Saykin, A. J. (2002). Executive dysfunction following traumatic brain injury: neural substrates and treatment strategies. NeuroRehabilitation, 17(4), 333-344.

McDonald, S. (2000). Exploring the cognitive basis of right-hemisphere pragmatic language disorders. Brain and language, 75(1), 82-107. doi:10.1006/brln.2000.2342

McDonald, S. (2013). Impairments in social cognition following severe traumatic brain injury. Journal of the International Neuropsychological Society, 19(3), 231-246. doi:10.1017/S1355617712001506

McDonald, S., Bornhofen, C., Shum, D., Long, E., Saunders, C., \& Neulinger, K. (2006). Reliability and validity of The Awareness of Social Inference Test (TASIT): a clinical test of social perception. Disability and rehabilitation, 28(24), 1529-1542. 
Running head: Heterogeneity of neuropsychological and pragmatics profiles

McDonald, S., Fisher, A., Flanagan, S., \& Honan, C. A. (2017). Impaired perception of sincerity after severe traumatic brain injury. Journal of neuropsychology, 11(2), 291-304. doi:10.1111/jnp.12086

McDonald, S., \& Flanagan, S. (2004). Social perception deficits after traumatic brain injury: Interaction between emotion recognition, mentalizing ability, and social communication. Neuropsychology, 18(3), 572-579. doi: 10.1037/0894-4105.18.3.572

McDonald, S., Gowland, A., Randall, R., Fisher, A., Osborne-Crowley, K., \& Honan, C. (2014). Cognitive factors underpinning poor expressive communication skills after traumatic brain injury: Theory of mind or executive function?. Neuropsychology, 28(5), 801-811. http://dx.doi.org/10.1037/neu0000089

McDonald, S., \& Pearce, S. (1996). Clinical insights into pragmatic theory: Frontal lobe deficits and sarcasm. Brain and language, 53(1), 81-104. doi:

https://doi.org/10.1006/brln.1996.0038

Mcdonald, S., \& Saunders, J. C. (2005). Differential impairment in recognition of emotion across different media in people with severe traumatic brain injury. Journal of the International Neuropsychological Society, 11(4), 392-399.

doi:10.10170S1355617705050447 
Running head: Heterogeneity of neuropsychological and pragmatics profiles

Meulenbroek, P., \& Turkstra, L. S. (2016). Job stability in skilled work and communication ability after moderate-severe traumatic brain injury. Disability and rehabilitation, 38(5), 452-461. doi: 10.3109/09638288.2015.1044621

Miyake, A., Friedman, N. P., Emerson, M. J., Witzki, A. H., Howerter, A., \& Wager, T. D. (2000). The unity and diversity of executive functions and their contributions to complex "frontal lobe" tasks: A latent variable analysis. Cognitive Psychology, 41, 49-100. doi:10.1006/cogp.1999.0734

Nasreddine, Z. S., Phillips, N. A., Bédirian, V., Charbonneau, S., Whitehead, V., Collin, I., ... \& Chertkow, H. (2005). The Montreal Cognitive Assessment, MoCA: a brief screening tool for mild cognitive impairment. Journal of the American Geriatrics Society, 53(4), 695699. doi: $10.1111 / \mathrm{j} .1532-5415.2005 .53221 . x$

Nespoulous, J.-L., Lecours, A. R., Lafond, D., Lemay, A., Puel, M., Joanette, Y., \& Rascol, A. (1992). Protocole Montréal-Toulouse d'examen linguistique de l'aphasie. MT-86 Module Standard Initial: M1A (2nd ed.), revised by Renée Béland \& Francine Giroux. Isbergues: L'Ortho-Édition

Pexman, P. M., \& Olineck, K. M. (2002). Understanding irony: How do stereotypes cue speaker intent? Journal of Language and Social Psychology, 21(3), 245-274. doi: https://doi.org/10.1177/0261927X02021003003

Prat, C. S., Mason, R. A., \& Just, M. A. (2012). An fMRI investigation of analogical mapping in metaphor comprehension: The influence of context and individual cognitive capacities 
Running head: Heterogeneity of neuropsychological and pragmatics profiles

on processing demands. Journal of Experimental Psychology: Learning, Memory, and Cognition, 38(2), 282-294. doi:10.1037/a0026037

Premack, D., \& Woodruff, G. (1978). Does the chimpanzee have a theory of mind? Behavioral and Brain Sciences, 1, 515-526. doi:

https://doi.org/10.1017/S0140525X00076512

Reitan, R. M. \& Wolfson, D. (1993). The Halstead-Reitan neuropsychological test battery. Tucson, AZ: Neuropsychology Press.

Rivière, E., Klein, M., \& Champagne-Lavau, M. (2018). Using context and prosody in irony understanding: Variability amongst individuals. Journal of Pragmatics, 138, 165-172. doi: https://doi.org/10.1016/j.pragma.2018.10.006

Rowley, D. A., Rogish, M., Alexander, T., \& Riggs, K. J. (2017). Cognitive correlates of pragmatic language comprehension in adult traumatic brain injury: A systematic review and meta-analyses. Brain injury, 31(12), 1564-1574. doi: 10.1080/02699052.2017.1341645

Shamay-Tsoory, S. G., Tomer, R., \& Aharon-Peretz, J. (2005). The neuroanatomical basis of understanding sarcasm and its relationship to social cognition. Neuropsychology, 19(3), 288-300. doi: 10.1037/0894-4105.19.3.288

Shibata, M., Toyomura, A., Itoh, H., \& Abe, J. I. (2010). Neural substrates of irony comprehension: A functional MRI study. Brain research, 1308, 114-123. doi:10.1016/j.brainres.2009.10.030 
Running head: Heterogeneity of neuropsychological and pragmatics profiles

Spotorno, N., Koun, E., Prado, J., Van Der Henst, J. B., \& Noveck, I. A. (2012). Neural evidence that utterance-processing entails mentalizing: the case of irony. NeuroImage, 63(1), 25-39. doi:10.1016/j.neuroimage.2012.06.046

Teasdale, G., \& Jennett, B. (1974). Assessment of coma and impaired consciousness: a practical scale. The Lancet, 304(7872), 81-84.

Tompkins, C. A. (2012). Rehabilitation for cognitive-communication disorders in right hemisphere brain damage. Archives of Physical Medicine and Rehabilitation, 93(1), S61S69. doi:10.1016/j.apmr.2011.10.015

Tompkins, C. A., Bloise, C. G., Timko, M. L., \& Baumgaertner, A. (1994). Working memory and inference revision in brain-damaged and normally aging adults. Journal of Speech, Language, and Hearing Research, 37(4), 896-912. doi:

https://doi.org/10.1044/jshr.3704.896

Uchiyama, H., Seki, A., Kageyama, H., Saito, D.N., Koeda, T., Ohno, K. \& Sadato, N. (2006). Neural substrates of sarcasm: a functional magnetic-resonance imaging study. Brain Res. 1124, 100-110. doi:10.1016/j.brainres.2006.09.088

Wakusawa, K., Sugiura, M., Sassa, Y., Jeong, H., Horie, K., Sato, S., .. \& Kawashima, R. (2007). Comprehension of implicit meanings in social situations involving irony: a functional MRI study. NeuroImage 37, 1417-1426. doi:10.1016/j.neuroimage.2007.06.013 
Running head: Heterogeneity of neuropsychological and pragmatics profiles

Ward, J.H. (1963). Hierarchical grouping to optimize an objective function. Journal of the American Statistical Association, 58, 236-244. doi:10.1080/01621459.1963.10500845

Weed, E. (2008). Theory of mind impairment in right hemisphere damage: A review of the evidence. International journal of speech-language pathology, 10(6), 414-424. doi:10.1080/17549500802455429

Winner, E., Brownell, H., Happé, F., Blum, A., \& Pincus, D. (1998). Distinguishing lies from jokes: Theory of mind deficits and discourse interpretation in right hemisphere braindamaged patients. Brain and Language, 62, 89-106. doi: https://doi.org/10.1006/brln.1997.1889

Zimmermann, N., Gindri, G., Oliveira, C. R. D., \& Fonseca, R. P. (2011). Pragmatic and executive functions in traumatic brain injury and right brain damage: An exploratory comparative study. Dementia \& neuropsychologia, 5(4), 337-345. doi: 10.1590/S1980$57642011 \mathrm{DN} 05040013$

Zinn, S., Bosworth, H. B., Hoenig, H. M., \& Swartzwelder, H. S. (2007). Executive function deficits in acute stroke. Archives of physical medicine and rehabilitation, 88(2), 173-180. doi:10.1016/j.apmr.2006.11.015 
Running head: Heterogeneity of neuropsychological and pragmatics profiles

\section{Footnotes}

${ }^{1}$ To control for the equivalence between the 3 lists of stimuli, a one-way ANOVA was performed on the total score calculated on questions on the speaker's intent of the task of irony. No significant difference between the three lists was found $(F(2,57)=0.45, p>.05)$. 
Running head: Heterogeneity of neuropsychological and pragmatics profiles

Tables and figures

Table 1.

Demographic and clinical data for the ABI participants

\begin{tabular}{|c|c|c|c|c|c|c|}
\hline Participants & Gender & $\begin{array}{l}\text { Age } \\
\text { (years) }\end{array}$ & $\begin{array}{l}\text { Education } \\
\text { (years) }\end{array}$ & Etiology & $\begin{array}{l}\text { Time post- } \\
\text { onset } \\
\text { (months) }\end{array}$ & Lesion site \\
\hline$\overline{\mathrm{ABI}}$ & $\bar{F}$ & 48 & 12 & TBI & 251 & Right fronto-temporo-parietal \\
\hline ABI2 & $\mathrm{M}$ & 36 & 12 & TBI & 12 & Bilateral frontal, subcortical - Diffuse injury \\
\hline $\mathrm{ABI} 3$ & $\mathrm{~F}$ & 57 & 13 & TBI & 60 & Right fronto-temporal, bilateral parietal - Diffuse injury \\
\hline $\mathrm{ABI} 4$ & M & 34 & 12 & TBI & 80 & Right fronto-temporal, subcortical - Diffuse injury \\
\hline ABI5 & $\mathrm{F}$ & 49 & 12 & TBI & 20 & Right fronto-temporo-parieto-occipital, left temporal \\
\hline ABI6 & $\mathrm{M}$ & 44 & 13 & TBI & 82 & Right fronto-temporal \\
\hline ABI7 & $\mathrm{M}$ & 24 & 16 & TBI & 24 & Right frontal \\
\hline ABI8 & $\mathrm{M}$ & 42 & 13 & TBI & 246 & Bilateral frontal, right temporal \\
\hline ABI9 & $\mathrm{F}$ & 59 & 9 & TBI & 149 & Bilateral frontal, right temporal, subcortical-Diffuse injury \\
\hline ABI10 & $\mathrm{M}$ & 49 & 13 & TBI & 45 & Bilateral frontal, right temporal, white matter \\
\hline ABI11 & $\mathrm{M}$ & 57 & 18 & TBI & 20 & Right frontal \\
\hline $\mathrm{ABI} 12$ & $\mathrm{M}$ & 59 & 16 & TBI & 44 & Bilateral frontal, left temporal \\
\hline ABI13 & $\mathrm{F}$ & 53 & 12 & TBI & 21 & Right fronto-temporal \\
\hline ABI14 & $\mathrm{M}$ & 49 & 12 & TBI & 14 & Bilateral fronto-parietal \\
\hline ABI15 & $\mathrm{M}$ & 59 & 18 & TBI & 17 & Right fronto-tempo-occipital - Diffuse injury \\
\hline ABI16 & $\mathrm{M}$ & 24 & 16 & TBI & 38 & Bilateral fronto-parietal \\
\hline ABI17 & $\mathrm{M}$ & 45 & 13 & TBI & 7 & Bilateral fronto-temporal, left parietal \\
\hline ABI18 & $\mathrm{F}$ & 52 & 12 & RHD & 30 & Right fronto-parieto-temporal \\
\hline ABI19 & $\mathrm{M}$ & 58 & 13 & RHD & 30 & Right anterior cerebral artery \\
\hline ABI20 & $\mathrm{F}$ & 54 & 9 & RHD & 18 & Right middle cerebral artery, right frontal \\
\hline $\mathrm{ABI} 21$ & $\mathrm{~F}$ & 54 & 12 & RHD & 16 & Right frontal \\
\hline $\mathrm{ABI} 22$ & $\mathrm{~F}$ & 59 & 11 & RHD & 62 & Right frontal \\
\hline ABI23 & $\mathrm{M}$ & 64 & 9 & RHD & 83 & Right middle cerebral artery \\
\hline
\end{tabular}


Running head: Heterogeneity of neuropsychological and pragmatics profiles

\begin{tabular}{lcccccc}
\hline ABI24 & M & 64 & 13 & RHD & 108 & Right fronto-occipital \\
ABI25 & M & 60 & 15 & RHD & 90 & Right frontal \\
ABI26 & F & 63 & 9 & RHD & 31 & Right frontal \\
ABI27 & M & 55 & 16 & RHD & 62 & Right middle cerebral artery \\
ABI28 & F & 52 & 11 & RHD & 5 & Right middle cerebral artery (M1, M2) \\
ABI29 & M & 64 & 13 & RHD & 3 & Right middle cerebral artery, subcortical \\
ABI30 & F & 45 & 12 & RHD & 6 & Right fronto-temporo-parietal \\
\hline
\end{tabular}

Note. TBI : traumatic brain injury, RHD: Right-Hemisphere Damage following a stroke 
Running head: Heterogeneity of neuropsychological and pragmatics profiles

Table 2.

Neuropsychological data for the acquired brain injured (ABI) participants and the healthy control (HC) participants

\begin{tabular}{|c|c|c|c|c|c|c|c|}
\hline & \multicolumn{2}{|c|}{ ABI } & \multicolumn{2}{|c|}{$\mathrm{HC}$} & \multirow[b]{2}{*}{$\mathrm{t}$} & \multirow[b]{2}{*}{ p-value } & \multirow[b]{2}{*}{ Cohen's $d$} \\
\hline & Mean & SD & Mean & SD & & & \\
\hline MoCA & 25.67 & 3.21 & 27.43 & 1.41 & 2.76 & $.009 *$ & 0.76 \\
\hline Digit SPAN (forward) & 8.20 & 2.25 & 9.83 & 2.44 & 2.70 & $.009 *$ & 0.67 \\
\hline Digit SPAN (backward) & 6.90 & 1.88 & 8.63 & 2.03 & 3.43 & $.001 *$ & 0.82 \\
\hline RST SPAN & 2.50 & 0.82 & 2.87 & 0.63 & 1.94 & .057 & - \\
\hline Letter fluency $(\mathrm{D}+\mathrm{F})$ & 21.43 & 7.84 & 27.53 & 7.40 & 3.10 & $.003 *$ & 0.77 \\
\hline Hayling (automatic) & 6.03 & 0.72 & 6.47 & 0.51 & 2.70 & $.009 *$ & 0.69 \\
\hline Hayling (inhibition) & 8.30 & 3.16 & 11.67 & 1.86 & 5.02 & $.0001 *$ & 1.10 \\
\hline Mini-SEA (total) & 27.90 & 7.65 & 33.67 & 4.69 & 3.50 & $.001 *$ & 0.84 \\
\hline Mini-SEA (faux pas) & 18.31 & 7.41 & 23.80 & 4.67 & 3.42 & $.001 *$ & 0.82 \\
\hline Mini-SEA (control) & 9.59 & 0.98 & 9.87 & 0.51 & 1.38 & .178 & - \\
\hline
\end{tabular}

Note: The symbol * indicates significant differences between the groups 
Running head: Heterogeneity of neuropsychological and pragmatics profiles

Table 3.

Correct responses to the questions on the speaker's intent and to the control questions in each condition in the acquired brain injured (ABI) participants and the healthy control (HC) participants

\begin{tabular}{|c|c|c|c|c|c|c|}
\hline & & & \multicolumn{2}{|c|}{$\mathrm{ABI}$} & \multicolumn{2}{|c|}{$\mathrm{HC}$} \\
\hline & & & Mean (/6) & $\mathrm{SD}$ & Mean (/6) & $\mathrm{SD}$ \\
\hline \multicolumn{7}{|c|}{ Questions on the speaker's intent } \\
\hline \multirow[t]{2}{*}{ Literal } & Low EF demand & & 5.77 & 0.57 & 5.87 & 0.35 \\
\hline & High EF demand & & 5.17 & 0.95 & 5.77 & 0.50 \\
\hline \multirow[t]{4}{*}{ Ironic } & Low EF demand & No marker & 5.57 & 0.94 & 5.67 & 0.48 \\
\hline & & With markers & 5.40 & 1.16 & 5.87 & 0.35 \\
\hline & High EF demand & No marker & 4.40 & 1.67 & 5.40 & 0.93 \\
\hline & & With markers & 5.17 & 1.12 & 5.43 & 0.82 \\
\hline \multicolumn{7}{|c|}{ Control questions } \\
\hline \multirow[t]{2}{*}{ Literal } & Low EF demand & & 5.77 & 0.57 & 5.97 & 0.18 \\
\hline & High EF demand & & 5.73 & 0.45 & 5.93 & 0.25 \\
\hline \multirow[t]{4}{*}{ Ironic } & Low EF demand & No marker & 5.90 & 0.31 & 5.93 & 0.25 \\
\hline & & With markers & 5.93 & 0.25 & 5.93 & 0.25 \\
\hline & High EF demand & No marker & 5.67 & 0.55 & 5.97 & 0.25 \\
\hline & & With markers & 5.77 & 0.50 & 5.93 & 0.25 \\
\hline
\end{tabular}


Running head: Heterogeneity of neuropsychological and pragmatics profiles

Table 4.

Sociodemographic and neuropsychological data for the healthy control (HC) group compared to participants with ABI with unimpaired irony comprehension (ABI-U) or impaired comprehension in ironic conditions (ABI-I), in ironic condition with no cue and high EF demand (ABI-INH), in literal condition with high EF demand (ABI-LH)

\begin{tabular}{|c|c|c|c|c|c|c|c|c|c|c|c|c|}
\hline & \multicolumn{2}{|c|}{ ABI-I } & \multicolumn{2}{|c|}{ ABI-INH } & \multicolumn{2}{|c|}{ ABI-LH } & \multicolumn{2}{|c|}{ ABI-U } & \multicolumn{2}{|c|}{$\mathrm{HC}$} & \multirow[b]{2}{*}{$\mathrm{H}$} & \multirow[b]{2}{*}{ p-value } \\
\hline & Mean & SD & Mean & SD & Mean & SD & Mean & SD & Mean & SD & & \\
\hline$\overline{\text { Age }}$ & 50.00 & 9.76 & 52.50 & 7.74 & 52.22 & 7.71 & 48.30 & 14.95 & 51.20 & 10.59 & 0.11 & .998 \\
\hline Educational level (years) & 12.75 & 0.50 & 11.83 & 2.64 & 12.33 & 1.23 & 14.30 & 2.95 & 12.83 & 2.57 & 4.63 & .328 \\
\hline Time post-onset (month) & 70.60 & 103.37 & 58.33 & 52.44 & 45.44 & 29.59 & 56.20 & 73.86 & - & - & 0.67 & .879 \\
\hline $\mathrm{MoCA}$ & 23.50 & 4.66 & 25.50 & 2.74 & 25.67 & 2.40 & 27.50 & 1.58 & 27.43 & 1.41 & 10.94 & .027 \\
\hline Digit SPAN (forward) & 7.25 & 1.26 & 8.17 & 3.43 & 8.00 & 1.41 & 9.10 & 2.23 & 9.83 & 2.44 & 9.50 & .05 \\
\hline Digit SPAN (backward) & 5.75 & 2.06 & 5.83 & 2.32 & 7.22 & 0.97 & 7.90 & 1.79 & 8.63 & 2.03 & 12.40 & $.015 £ \$$ \\
\hline RST SPAN & 2.00 & 0.82 & 2.50 & 0.55 & 2.33 & 0.71 & 3.00 & 0.82 & 2.87 & 0.63 & 10.82 & .029 \\
\hline Letter fluency $(\mathrm{D}+\mathrm{F})$ & 20.25 & 8.73 & 21.17 & 6.21 & 22.44 & 8.38 & 22.50 & 8.10 & 27.53 & 7.40 & 8.44 & .077 \\
\hline Hayling (automatic) & 5.25 & 1.50 & 6.00 & 0.00 & 6.22 & 0.44 & 6.30 & 0.48 & 6.47 & 0.51 & 12.42 & $.015 \$$ \\
\hline Hayling (inhibition) & 5.50 & 2.52 & 7.00 & 3.16 & 9.00 & 2.83 & 9.90 & 2.89 & 11.67 & 1.86 & 23.25 & $.0001 ! £ \$$ \\
\hline Mini-SEA (total) & 17.75 & 8.06 & 30.33 & 2.25 & 28.44 & 6.56 & 30.00 & 8.03 & 33.67 & 4.69 & 14.69 & $.005 \$$ \\
\hline Mini-SEA (faux pas) & 8.75 & 6.95 & 20.67 & 1.51 & 19.11 & 6.77 & 20.00 & 8.03 & 23.80 & 4.67 & 14.00 & $.007 \$$ \\
\hline Mini-SEA (control) & 9.00 & 2.00 & 9.67 & 0.82 & 9.33 & 1.00 & 10.00 & 0.00 & 9.87 & 0.51 & 6.84 & .144 \\
\hline
\end{tabular}

Note : The symbols !, £ and \$ indicate significant differences between the groups with ! HC $\neq$

ABI-LH; $£$ HC $\neq$ ABI-INH; \$ HC $\neq$ ABI-I 
Running head: Heterogeneity of neuropsychological and pragmatics profiles

Table 5.

Correct responses to the questions on the speaker's intent and to the control questions in each condition in the healthy control (HC) group compared to participants with ABI with Unimpaired irony comprehension (ABI-U) or impaired comprehension in Ironic conditions (ABI-I), in Ironic condition with No marker and High EF demand (ABI-INH), in Literal condition with High EF demand (ABI-LH) 
Running head: Heterogeneity of neuropsychological and pragmatics profiles

\begin{tabular}{|c|c|c|c|c|c|c|c|c|c|c|c|c|c|c|}
\hline & & & \multicolumn{2}{|c|}{ ABI-I } & \multicolumn{2}{|c|}{ ABI-INH } & \multicolumn{2}{|c|}{ ABI-LH } & \multicolumn{2}{|c|}{ ABI-U } & \multicolumn{2}{|c|}{$\mathrm{HC}$} & \multirow[b]{2}{*}{$\mathrm{H}$} & \multirow[b]{2}{*}{ p-value } \\
\hline & & & Mean & $\mathrm{SD}$ & Mean & $\mathrm{SD}$ & Mean & $\mathrm{SD}$ & Mean & $\mathrm{SD}$ & Mean & $\mathrm{SD}$ & & \\
\hline \multicolumn{15}{|c|}{ Questions on the speaker's intent } \\
\hline \multirow[t]{2}{*}{ Literal } & Low EF demand & & 5.60 & 0.55 & 5.50 & 0.84 & 5.78 & 0.67 & 6.00 & 0.00 & 5.87 & 0.35 & 5.82 & .213 \\
\hline & High EF demand & & 4.80 & 1.30 & 5.33 & 0.52 & 4.33 & 0.71 & 6.00 & 0.00 & 5.77 & 0.50 & 30.25 & $.0001 ！$ \\
\hline \multirow[t]{4}{*}{ Ironic } & Low EF demand & No marker & 4.00 & 1.41 & 5.83 & 0.41 & 5.89 & 0.33 & 5.90 & 0.32 & 5.67 & 0.48 & 13.61 & $.009 \$$ \\
\hline & & With markers & 3.00 & 0.71 & 5.83 & 0.41 & 5.89 & 0.33 & 5.90 & 0.32 & 5.87 & 0.35 & 27.91 & $.0001 \$$ \\
\hline & High EF demand & No marker & 1.60 & 1.14 & 3.33 & 0.82 & 5.33 & 0.50 & 5.60 & 0.52 & 5.40 & 0.93 & 28.33 & $.0001 £ \$$ \\
\hline & & With markers & 3.20 & 0.84 & 5.83 & 0.41 & 5.11 & 0.78 & 5.80 & 0.42 & 5.43 & 0.82 & 20.15 & $.0001 \$$ \\
\hline \multicolumn{15}{|c|}{ Control questions } \\
\hline \multirow[t]{2}{*}{ Literal } & Low EF demand & No marker & 5.60 & 0.55 & 5.50 & 0.84 & 5.78 & 0.67 & 6.00 & 0.00 & 5.97 & 0.18 & 10.84 & .028 \\
\hline & High EF demand & With markers & 5.60 & 0.55 & 5.83 & 0.41 & 5.56 & 0.53 & 5.90 & 0.32 & 5.93 & 0.25 & 9.28 & .054 \\
\hline \multirow[t]{4}{*}{ Ironic } & Low EF demand & No marker & 5.80 & 0.45 & 5.83 & 0.41 & 5.89 & 0.33 & 6.00 & 0.00 & 5.93 & 0.25 & 2.50 & .644 \\
\hline & & With markers & 5.80 & 0.45 & 5.83 & 0.41 & 6.00 & 0.00 & 6.00 & 0.00 & 5.93 & 0.25 & 3.69 & .450 \\
\hline & High EF demand & No marker & 5.20 & 0.84 & 5.33 & 0.52 & 5.89 & 0.33 & 5.90 & 0.32 & 5.97 & 0.18 & 21.82 & $.0002 £$ \\
\hline & & With markers & 5.40 & 0.89 & 5.83 & 0.41 & 5.67 & 0.50 & 6.00 & 0.00 & 5.93 & 0.25 & 9.11 & .059 \\
\hline
\end{tabular}

Note $:$ The symbols !, £ and \$ indicate significant differences between the groups with ! HC $\neq$ ABI-LH; $£$ HC $\neq \mathrm{ABI}-\mathrm{INH} ; \$ \mathrm{HC} \neq \mathrm{ABI}-\mathrm{I}$ 
Running head: Heterogeneity of neuropsychological and pragmatics profiles

Figure 1. Example and structure of the irony comprehension task

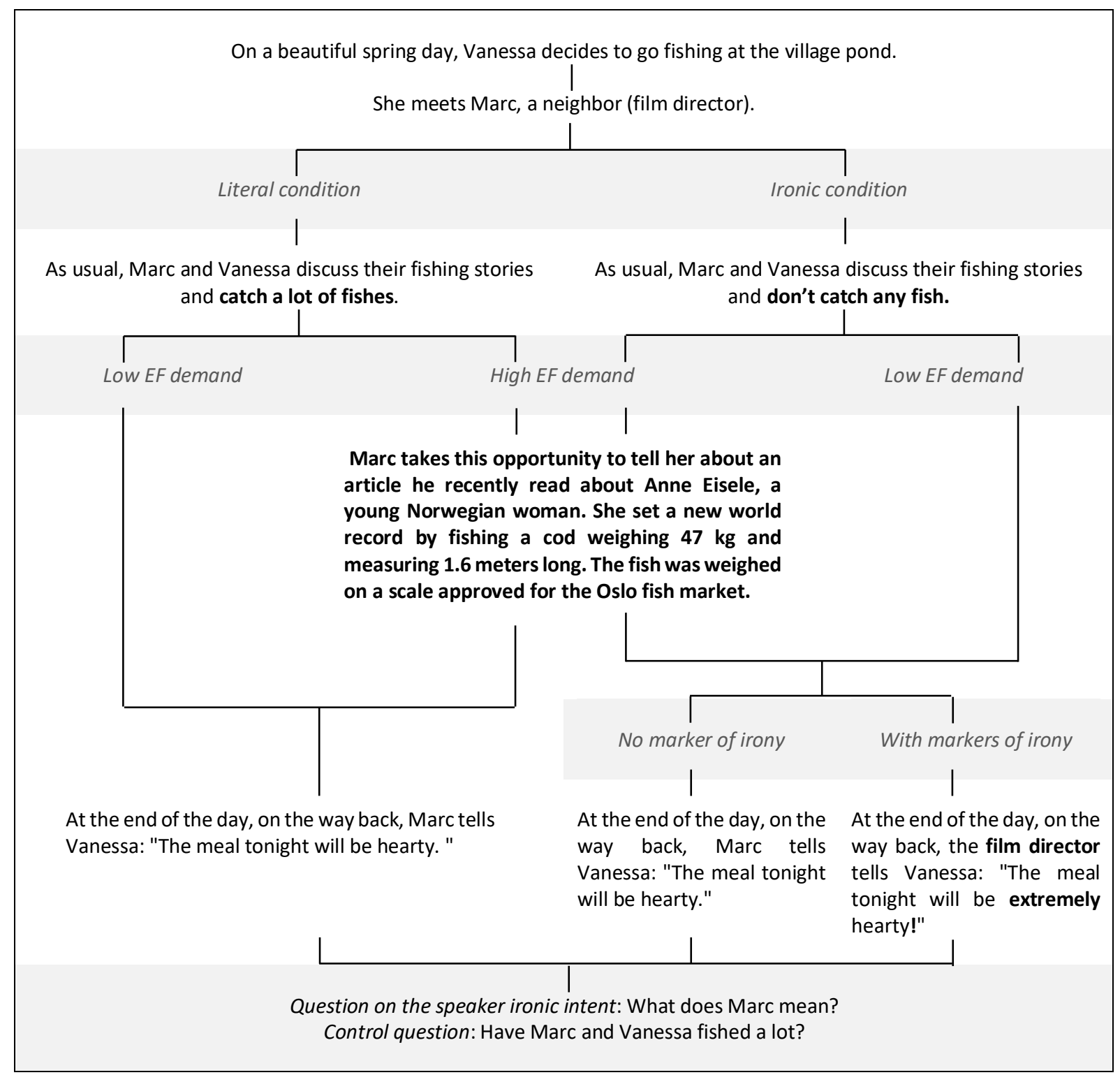

Figure 1. Example and structure of the irony comprehension task varying the context (literal vs. ironic), the EF demand (low vs. high) and, in the ironic conditions, the presence of markers of irony (no vs. with) 
Running head: Heterogeneity of neuropsychological and pragmatics profiles

Figure 2. Dendogram using the Ward's method on the ABI group

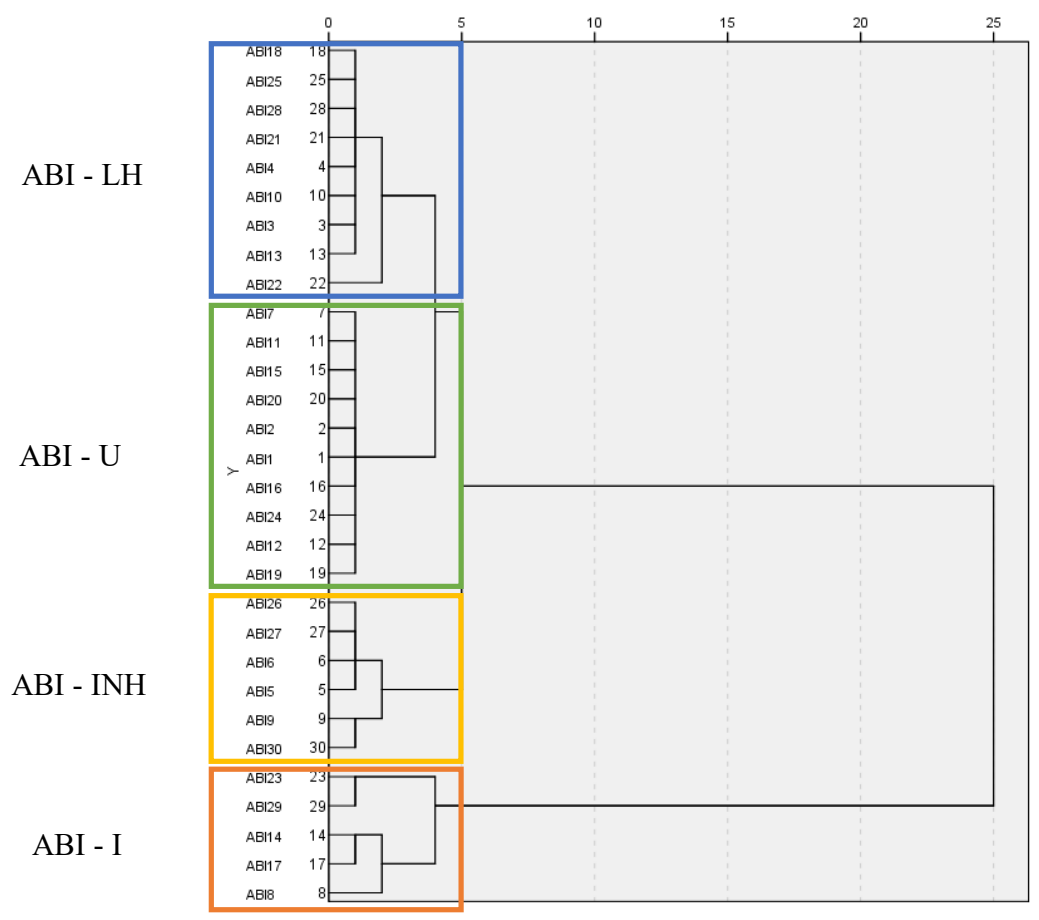

Figure 2. Each ABI participant represents a line on the ordinate axis of the figure. ABI-LH: participants with $\mathrm{ABI}$ impaired in the literal condition with high EF demand; $\mathrm{ABI}-\mathrm{U}$ : participants with ABI unimpaired on ironic evaluation; ABI-INH: participants with ABI impaired in the ironic condition with no marker of irony and high EF demand; ABI-I: participants with $\mathrm{ABI}$ impaired in all the ironic conditions 